\title{
Nonlinear numerical analysis of composite slabs with steel decking
}

\section{Análise numérica não linear de lajes de concreto com fôrma de aço incorporada}

\author{
A. R. SILVA \\ amilton@em.ufop.br \\ https://orcid.org/0000-0002-7122-252X \\ P. B. SILVA a \\ engpriscilabrandao@gmail.com \\ https://orcid.org/0000-0002-7412-6728
}

\begin{abstract}
The composite slabs behavior is governed by longitudinal shear at the interface between the steel deck and concrete, which is developed in slabs under simple bending. The $\mathrm{m}-\mathrm{k}$ method and the partial connection method, that are used in the evaluation of shear strength at the steel-concrete interface of composite slabs, are based on expensive and long-term experimental tests. The main objective of this work is to implement a finite element model for nonlinear numerical analysis of concrete slabs with steel decking. For this, flat shell elements are implemented, considering Reissner-Mindlin and Kirchoff plate theories, bar elements, considering the beam theory of Tymoshenko, and interface elements. In the numerical analyzes presented in the present work, the steel deck and the concrete slab, of thickness given by the total height of the slab less the height of the steel deck, are modeled with flat shell elements. The concrete rib is modeled with bar elements. The contact between steel deck and concrete is modeled through interface elements. The geometric and material nonlinearities are considered in the numerical analysis. The analyzed examples validate the numerical model suggested in this work, presenting the advantage of using a two-dimensional discretization of the problem while in comparative numerical models are uses a three-dimensional discretization of the concrete slab.
\end{abstract}

Keywords: composite slabs, flat shell elements, partial connection, longitudinal shear.

\section{Resumo}

O comportamento das lajes mistas é governado pelo cisalhamento longitudinal na interface entre o aço e o concreto, que é desenvolvido em lajes sob flexão simples. O método m-k e o método da interação parcial, utilizados no cálculo da resistência ao cisalhamento na interface aço-concreto de lajes mistas, são baseados em ensaios experimentais caros e de longa duração. O objetivo principal desse trabalho é implementar um modelo de elementos finitos para análise numérica não linear de lajes de concreto com fôrma de aço incorporada, para isso são implementados elementos planos de casca, considerando as teorias de placa de Reissner-Mindlin e Kirchoff, elementos de barra, considerando a teoria de viga de Timoshenko, e elementos de interface. Nas análises numéricas apresentadas nesse trabalho a fôrma de aço e a laje de concreto, de espessura dada pela altura total da laje menos a altura da forma de aço, são modeladas com elementos planos de casca. A nervura de concreto é modelada com elementos de barra. O contato entre a fôrma de aço e o concreto é modelado através de elementos de interface. As não linearidades geométrica e física são consideradas na análise numérica. Os exemplos analisados validam o modelo numérico sugerido neste trabalho apresentando a vantagem de usar uma discretização bidimensional do problema enquanto os modelos numéricos comparativos utilizam uma discretização tridimensional da laje de concreto.

Palavras-chave: lajes mistas, elementos planos de casca, conexão parcial, cisalhamento longitudinal.

Universidade Federal de Ouro Preto, Escola de Minas, Departamento de Engenharia Civil, Programa de Pós Graduação em Engenharia Civil, Ouro Preto, MG, Brazil. 


\section{Introduction}

The composite slabs consist of a cold-formed steel profiled sheeting, known as steel deck, and a concrete slab. The steel profiled sheeting should be designed to support the construction loads and, after the concrete has hardened, act as part or all the tensile reinforcement. The concrete must be designed to support compression and vertical shear stresses. This structural system arised in the late 1930s and became popular during the late 1980s [1]. The composite slabs began to be used in Brazil in the 1990s and have been popularized ever since [2]

The most common failure mechanism in composite slabs is longitudinal shear failure at the interface between the steel and concrete. There are several factors that influence the longitudinal shear strength of the interface, such as the steel sheeting and the concrete slab thicknesses, the geometry of the steel sheeting, the depth and slope of the embossments and the distance between them, the load configuration, the type of anchorage at the ends and the shear span. The main characteristic of failure mechanism due to longitudinal shear is the sliding of the concrete over the steel decking that occurs for a load much smaller than the corresponding load to the flexural strength [1]. The NBR 8800 [3] and EUROCODE 4 [4] recommend the $\mathrm{m}-\mathrm{k}$ method and the partial connection method to verify this failure mechanism. These methods rely on real-scale experimental trials, which are expensive and time-consuming. The values of $m$ and $k$ are different for each type of steel sheeting requiring experimental tests for each variation of the profiled steel sheet [5].

The numerical analysis of composite slabs using the finite element method is proposed as an economical alternative to the real-scale bending tests, enabling a reduction in these tests' frequency [6]. The authors point out that the correct modeling of the shear stress versus shear stress curve at the steel-concrete interface is the factor that most affects the accuracy of numerical results. A method dependent of few parameters for the modeling of the shear stress versus slip curve is also proposed [7].

In most numerical analysis papers of composite slabs $[7,8,9,10,11$ and 12] the authors simulate the concrete slab by three-dimensional elements, the steel decking by flat shell elements, and the connec- tion by using interface elements. In this paper only flat shell elements, beam elements and interface elements are used, providing an analysis of lower computational cost than to the that uses threedimensional discretization of the concrete part of the composite slab. In a new type of composite slabs, proposed by Ferrer et al. [13], it is suggested altering the trapezoidal steel sheeting, replacing the embossments by holes in the inclined parts of the steel decking. According to the obtained results, this type of bonding is equivalent to the total connection between the materials, because the rupture of the slabs occurred with the total plastification of the sections.

This paper considers the physical nonlinearity the flat shell element and it is subdivided into layers which are considered in a plane state plane of stress and may have different mechanical characteristics. For the case of the flat shell element in reinforced concrete, the steel reinforcements are considered as equivalent steel layers with stiffness only in the direction of the reinforcement. This nonlinear physical model for the flat shell element of concrete has been used previously [14,15, 16 and 17].

In the flat shell element formulation, the plate theories of ReissnerMindlin and Kirchhoff are considered. The Reissner-Mindlin theory can generate numerical errors in the analysis of thin plates with low discretization due to non-compatibility of the form functions in evaluating the shear deformation, which in these cases tends to be very small. This shear locking is not verified in Kirchhoff's plate theory, although the formulation for this theory is somewhat more complex, as the rotations are associated with the derived of the perpendicular displacement to the plane of the plate. Details of some formulations of flat shell element considering Kirchhoff's plate theory can be found elsewhere [18, 19, 20 and 21].

\section{Composite slabs contact mechanism behavior}

The behavior of the contact interface between the steel decking and the concrete of composite slabs has been extensively studied. From the experimental tests, pull-out test, push-off test and bending test, the data require to generate curves that relate the longitudinal slip with the shear stress were obtained [22].

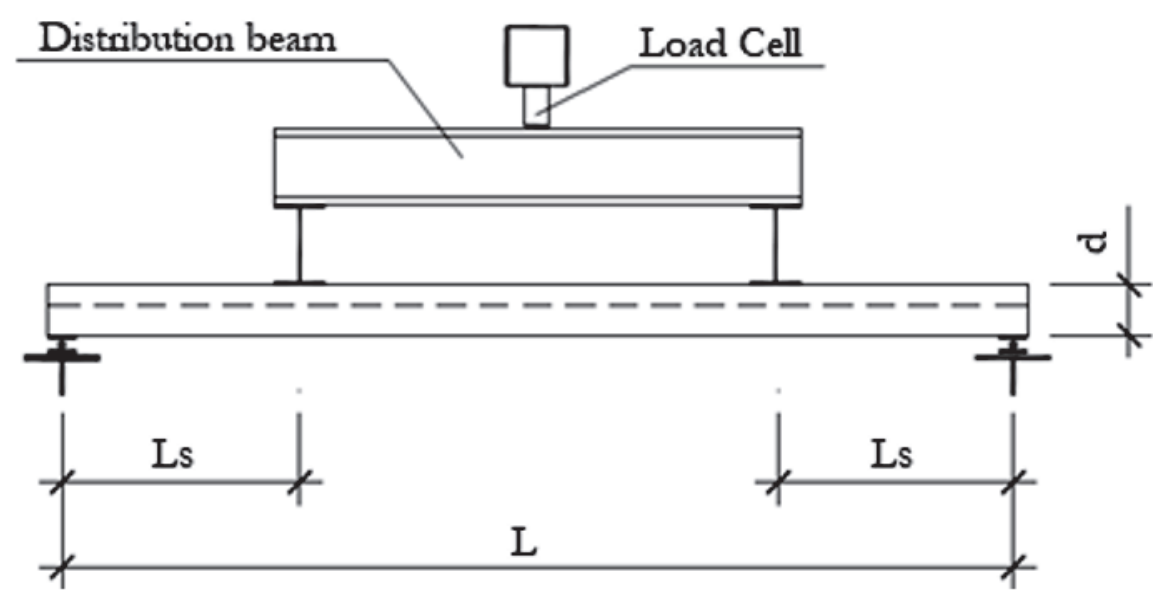

Figure 1

Set up of the bending test (adapted from [9]) 


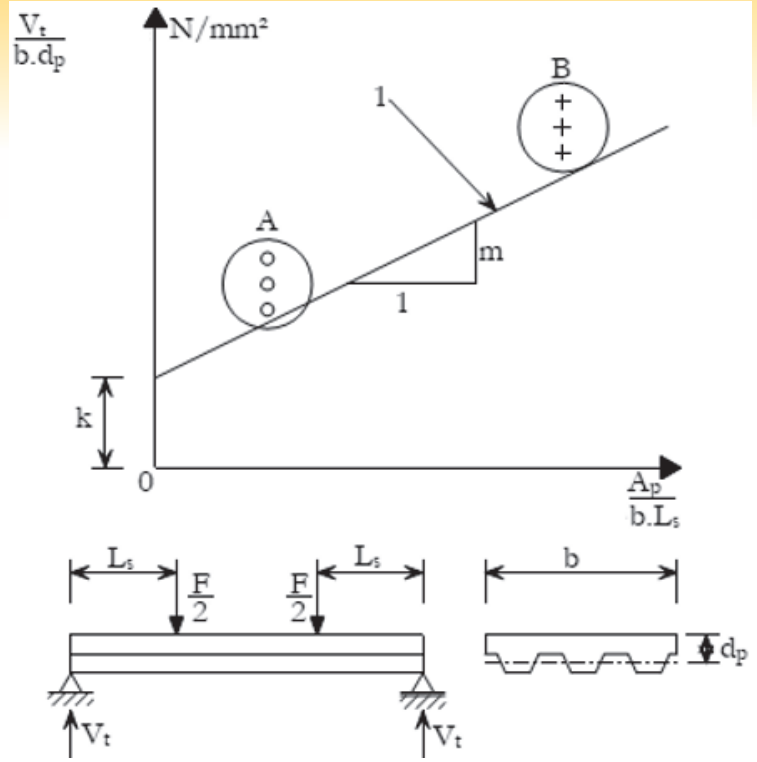

Figure 2

Determination of the parameters $m$ and $k$ [3]

The main problem of both pull-out and push-off tests is that, they do not capture the curvature effects due to bending of the slab and of the ratio between the length of shear span and the effective concrete thickness [6]. Therefore, it is suggested the bending test shown in Figure 1 which consists in the application of two symmetrical loads according to the supports of the composite slab subjecting it to pure and simple bending. As a result of this test, the parameters $m$ and $k$ used to determine the design longitudinal shear force (Eq. 1) of composite slabs using the studied steel sheeting are determined. In Eq. 1, $d_{p}$ is the distance from the upper face of the concrete slab to the geometric center of the effective section of the steel sheeting, $b$ is the slab unit width, $L_{s}$ is the shear span and $A_{s}$ is the area of the effective section of the steel sheeting.

$V=b d_{p}\left[\left(\frac{m A_{s}}{b L_{s}}\right)+k\right]$

In the $m-k$ method, the Eq. 1 is rewritten as a linear equation, $m$ being the angular coefficient and $k$ the linear coefficient [23]. With this consideration, two groups of three tests are analyzed for each steel decking model, as indicated in Figure 2, by regions A and B.

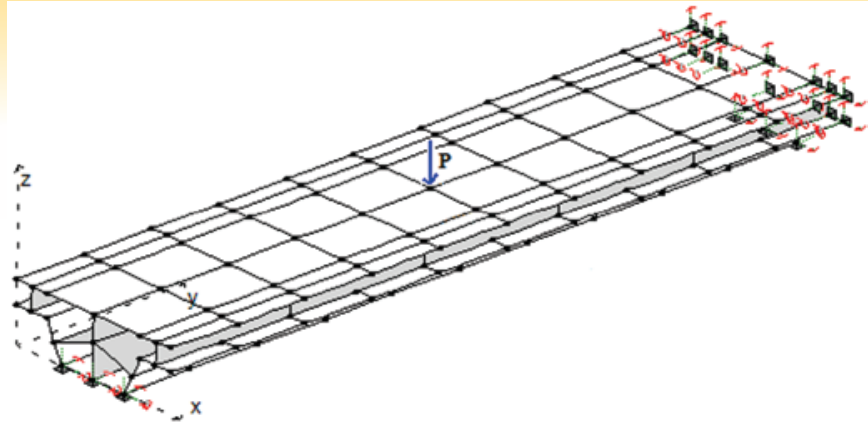

Figure 3

Composite slab model

Both groups are defined in such a way that one group is formed by compact composite slabs and the other of slender composite slabs. With the values obtained from the tests, a linear regression is done using the least squares method, and the parameters $m$ and $k$ are generated, as shown in Figure 2.

The bending test for the study of mechanisms that influence the transfer of longitudinal shear in composite slabs were used [1 and 8]. A methodology for the three-dimensional nonlinear modeling of the pull-out test to simulate the slip behavior on the contact considering it with friction was also used [24]. It was concluded that the parameters that most influenced the slip resistance are the embossments transversal slope, the steel sheeting thickness and the friction surface conditions. Other authors [25, 26 and 27] have shown that the ends anchoring the composite slabs improve their structural behavior.

\section{Computational implementation}

In Figure 3 it is shown the discretization of a composite slab in flat shell elements, beam elements and interface elements. In this figure the composite slab has simple supports at the ends, perpendicular to the direction of the ribs and is free in the remainder of its contour. Therefore, the composite slab tends to flex only in the $y z$ plane of the figure. Due to this, together with the symmetry of the conditions of support and loading, only one rib of the composite slab and half of its span is simulated.

Figure 4 includes the elements used in the discretization of the composite slab. Two interface elements are used to model the steel-concrete interface, one that connects two flat shell elements

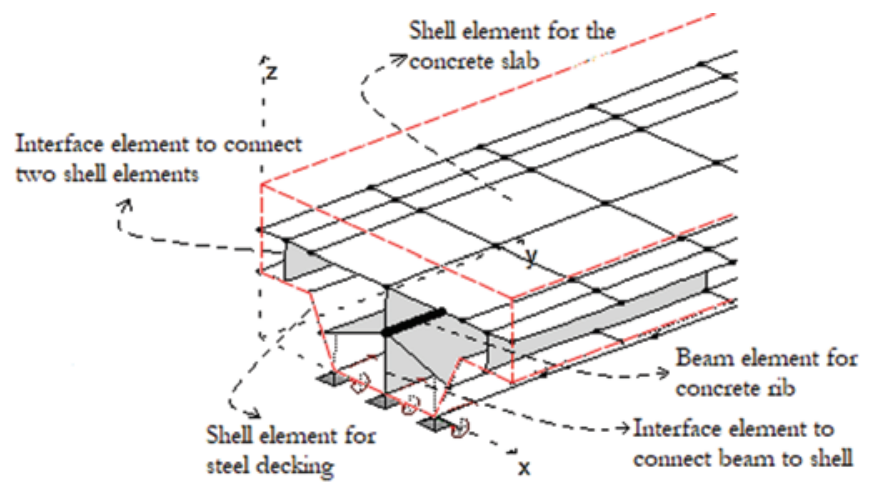

a

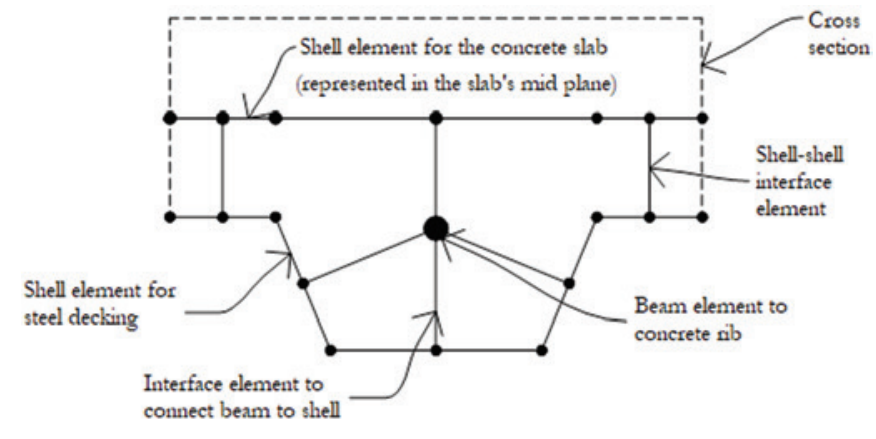

b

Figure 4

Representation of the used elements: (a) perspective view, (b) plane xz view 


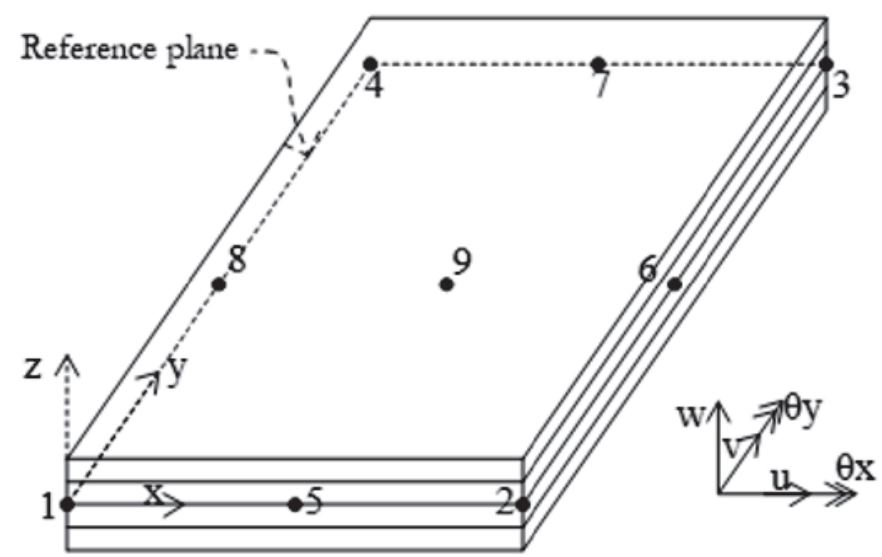

Figure 5

Flat shell element with nine nodes and divided in layers

and the other that connects beam element to the shell element. In the case of the interface element connecting the concrete rib to the concrete slab the rib there is no sliding plane in that interface and a high value is attributed to the stiffness of the connection.

In the following items the formulations of the used elements in slabs numerical simulation are shown. Further formulations details can be formed elsewhere [28 and 29].

\subsection{Thick flat shell element}

The thick flat shell element implemented for the nonlinear analysis of composite slabs includes nine nodes, five degrees of freedom per node at the local level, as shown in Figure 5. Physical nonlinearity is considered by dividing the section into several layers, as given by Huang et al. [17]: (i) The elements are composed of layers of steel or concrete, and sliding between the layers is prevented; (ii) Each layer may have different mechanical properties and independent stress-strain relationships; (iii) The reinforcements are considered as an equivalent layer of steel with stiffness only in the bar direction; (iv) The concrete layers are in a plane stress state and the concrete is considered orthotropic after cracking.

According to the kinematic assumptions of Reissner-Mindlin plate theory, a point in the domain of the plate element can move according to Equations 2 to 4 . In these equations $u^{0}, v^{0}$ and $w^{0}$ are the translations of the reference plane of the flat shell element in the directions $x, y$ and $z$. $\theta_{x}$ and $\theta_{y}$ are the rotations of the sections with respect to the $x$ and $y$ axes. $z$ is the position of the fiber in relation to the average surface along the thickness of the flat shell element where it is desired to evaluate the displacements. To facilitate notation, the zero superscript is omitted in the following equations.

$$
\begin{aligned}
& u(x, y, z)=u^{0}(x, y)+z \theta_{y}(x, y) \\
& v(x, y, z)=v^{0}(x, y)-z \theta_{x}(x, y) \\
& w(x, y, z)=w^{0}(x, y)
\end{aligned}
$$

Applying Equations 2 to 4 to the Green-Lagrange strain-displacement relationship $\varepsilon_{i j}=\frac{1}{2}\left(u_{i, j}+u_{j, i}+u_{k, i} u_{k, j}\right)$ and neglecting the variation of $w$ with $z$, Von Karman's hypotheses, it is obtained the strain equations reacted nonlinearly with displacements (geometric nonlinearity). The stress-strain relationships for the concrete used in this paper are the models defined by the European Concrete Committee [30]. For the behavior of the concrete after the cracking, a bi-linear model was adopted for the degradation of the elasticity modulus similar to that suggested by Rots et al. [31] and used by Huang et al. [17]. In the case of reinforced concrete, the steel of the reinforcing bars is considered perfectly plastic elastic.

For nonlinear analysis of the problem, an incremental method with displacement control is used in this paper. In the used method, a small step size is adopted, and a correction is made at each step in the stiffness matrix by calculating the mean tangent [28]. In the displacements increments of this method is considered linear material with modulus of elasticity given by the tangent to the stressstrain curve and valid the Hooke's law constitutive relation for the analyzed problem.

The concrete has orthotropic behavior after cracking or crushing. Considering the layers in stress plane state, the principal directions indicated in this paper by subscripts 1 and 2 are defined. If the principal deformations $\left(\varepsilon_{1}\right.$ and $\left.\varepsilon_{2}\right)$ are within the failure region, the concrete is considered orthotropic with the decoupled stress-strain relationship for the principal directions as given by the constitutive matrix given by Eq. 5 .

$\mathbf{D}_{12}=\left[\begin{array}{ccccc}E_{1} & 0 & 0 & 0 & 0 \\ & E_{2} & 0 & 0 & 0 \\ & & \frac{1}{2}\left(G_{1}+G_{2}\right) & 0 & 0 \\ & & & G_{1} & 0 \\ \text { Sim. } & & & & G_{2}\end{array}\right]$

In the previous equation, $E_{1}$ and $E_{2}$ are given by the tangents of the concrete stress-strain curve at points $\varepsilon=\varepsilon_{1}$ and $\varepsilon=\varepsilon_{2}$, respectively. Already $\mathrm{G}_{1}=0.5 \mathrm{E}_{1} /(1+\mathrm{v})$ and $\mathrm{G}_{2}=0.5 \mathrm{E}_{2} /(1+\mathrm{v})$. $\phi$ is the angle of rotation of the principal axes in relation to the $x$ and $y$ axes, the stiffness matrix in the direction of the orthogonal axes $x$ and $y$ can be obtained from $D_{x y}$

$\mathbf{D}_{x y}=\left[\begin{array}{ccccc}D_{11} & D_{12} & D_{13} & 0 & 0 \\ & D_{22} & D_{23} & 0 & 0 \\ & & D_{33} & 0 & 0 \\ & & & D_{44} & D_{45} \\ \text { Sim. } & & & & D_{55}\end{array}\right]$

In Eq. 6,

$D_{11}=E_{1} \cos ^{4} \phi+E_{2} \sin ^{4} \phi+\frac{1}{2}\left(G_{1}+G_{2}\right) \sin ^{2}(2 \phi)$,

$D_{12}=\frac{1}{4} \sin ^{2}(2 \phi)\left(E_{1}+E_{2}-4\left(G_{1}+G_{2}\right)\right.$,

$D_{13}=\frac{1}{2} \sin ^{2} \phi\left(E_{1} \cos ^{2} \phi-E_{2} \sin ^{2} \phi-\left(G_{1}+G_{2}\right) \cos (2 \phi)\right)$,

$D_{22}=E_{1} \sin ^{4} \phi+E_{2} \cos ^{4} \phi+\frac{1}{2}\left(G_{1}+G_{2}\right) \sin ^{2}(2 \phi)$,

$D_{23}=\frac{1}{2} \sin ^{2} \phi\left(E_{1} \sin ^{2} \phi-E_{2} \cos ^{2} \phi+\left(G_{1}+G_{2}\right) \cos (2 \phi)\right)$,

$D_{33}=\frac{1}{4} \sin ^{2}(2 \phi)\left(E_{1}+E_{2}\right)+\frac{1}{2}\left(G_{1}+G_{2}\right) \cos ^{2}(2 \phi)$, 
$D_{44}=G_{1} \cos ^{2} \phi+G_{2} \sin ^{2} \phi$

$D_{45}=\frac{1}{2}\left(G_{1}-G_{2}\right) \sin (2 \phi)$, and $D_{55}=G_{1} \sin ^{2} \phi+G_{2} \cos ^{2} \phi$.

For the particular case of isotropic material, observed when the principal deformations are outside the concrete failure region, $\mathrm{E} 1=\mathrm{E} 2=\mathrm{E}, \mathrm{G} 1=\mathrm{G} 2=\mathrm{G}$ and the $\mathrm{D}_{\mathrm{xy}}$ matrix of Eq. 6 reduces the traditional shape of the constitutive matrix of Hooke's general law for the problem in question.

From a virtual deformation field compatible with the flat shell element and applying the virtual works principle arrives at the internal forces vector given by the following equation.

$$
\boldsymbol{f}_{\text {int }}=\iint_{A}\left[\begin{array}{c}
N_{x} \boldsymbol{\Phi}_{, x}+N_{x y} \boldsymbol{\Phi}_{, y} \\
N_{x y} \boldsymbol{\Phi}_{, x}+N_{y} \boldsymbol{\Phi}_{, y} \\
Q_{x z} \boldsymbol{\Phi}_{, x}+Q_{y z} \boldsymbol{\Phi}_{, y}+w_{, x} N_{x} \boldsymbol{\Phi}_{, x}+w_{, y} N_{y} \boldsymbol{\Phi}_{, y}+N_{x y}\left(w_{y} \boldsymbol{\Phi}_{, x}+w_{, x} \boldsymbol{\Phi}_{, y}\right) \\
-M_{x y} \boldsymbol{\Phi}_{, x}-M_{x} \boldsymbol{\Phi}_{, y}-Q_{y z} \boldsymbol{\Phi} \\
M_{y} \boldsymbol{\Phi}_{, x}+M_{x y} \boldsymbol{\Phi}_{, y}+Q_{x z} \boldsymbol{\Phi}
\end{array}\right] d A
$$

In Eq. 7, $N_{x}, N_{y}, N_{x y}, Q_{x z}, Q_{y z}, M_{y}, M_{x}$ and $M_{x y}$ are scalars given by the forces per unit length obtained from the integral along the thickness of the normal and shear stresses in the orthogonal section.

Considering that the Reissner-Mindlin's plate theory is used in this formulation, translational and rotational displacements can be independently interpolated, so the interpolation functions for the element are given by biquadratic polynomials $\left(N_{i}, i=1, \ldots, 9\right)$ in relation to parametric coordinates. The term $\Phi$ in Eq. 7 is a nine-term vector formed by these polynomials.

To solve the nonlinear equilibrium problem $f_{\text {int }}-f_{\text {ext }}=0$, the NewtonRaphson method is used. Thus, the tangent stiffness matrix must be obtained. Being fext constant with respect to nodal displacements, the tangent stiffness matrix is given by $\mathbf{K}=\frac{\partial \mathbf{f}_{\text {int }}}{\partial \mathbf{q}}$.

$$
\mathbf{K}=\iint_{A}\left[\begin{array}{c}
\boldsymbol{\Phi}_{, x}\left(\frac{\partial N_{x}}{\partial \mathbf{q}}\right)^{T}+\boldsymbol{\Phi}_{, y}\left(\frac{\partial N_{x y}}{\partial \mathbf{q}}\right)^{T} \\
\boldsymbol{\Phi}_{, x}\left(\frac{\partial N_{x y}}{\partial \mathbf{q}}\right)^{T}+\boldsymbol{\Phi}_{, y}\left(\frac{\partial N_{y}}{\partial \mathbf{q}}\right)^{T} \\
\boldsymbol{\Phi}_{, x}\left(\frac{\partial Q_{x y}}{\partial \mathbf{q}}\right)^{T}+\boldsymbol{\Phi}_{, y}\left(\frac{\partial Q_{y z}}{\partial \mathbf{q}}\right)^{T}+\boldsymbol{\Phi}_{, x} \boldsymbol{\Psi}_{1}+\boldsymbol{\Phi}_{, y} \boldsymbol{\Psi}_{2} \\
-\boldsymbol{\Phi}_{, x}\left(\frac{\partial M_{x y}}{\partial \mathbf{q}}\right)^{T}-\boldsymbol{\Phi}_{, y}\left(\frac{\partial M_{x}}{\partial \mathbf{q}}\right)^{T}-\boldsymbol{\Phi}\left(\frac{\partial Q_{y z}}{\partial \mathbf{q}}\right)^{T} \\
\boldsymbol{\Phi}_{, x}\left(\frac{\partial M_{y}}{\partial \mathbf{q}}\right)^{T}+\boldsymbol{\Phi}_{, y}\left(\frac{\partial M_{x y}}{\partial \mathbf{q}}\right)^{T}+\boldsymbol{\Phi}\left(\frac{\partial Q_{x z}}{\partial \mathbf{q}}\right)^{T}
\end{array}\right] d A
$$

In Eq. 8, q is a column vector with 45 terms representing the nodal displacements of the shell element, $\Psi_{1}$ and $\Psi_{2}$ are column vectors with 45 terms as shown in the following expressions.

$$
\begin{aligned}
& \boldsymbol{\Psi}_{1}=\left(\frac{\partial w_{, x}}{\partial \mathbf{q}} N_{x}+\frac{\partial N_{x}}{\partial \mathbf{q}} w_{, x}\right)^{T}+\left(\frac{\partial w_{, y}}{\partial \mathbf{q}} N_{x y}+\frac{\partial N_{x y}}{\partial \mathbf{q}} w_{, y}\right)^{T} \\
& \boldsymbol{\Psi}_{2}=\left(\frac{\partial w_{, y}}{\partial \mathbf{q}} N_{y}+\frac{\partial N_{y}}{\partial \mathbf{q}} w_{, y}\right)^{T}+\left(\frac{\partial w_{, x}}{\partial \mathbf{q}} N_{x y}+\frac{\partial N_{x y}}{\partial \mathbf{q}} w_{, x}\right)^{T}
\end{aligned}
$$

\subsection{Thin flat shell element}

The finite element implemented for the thin flat shell analysis is the four-node rectangular element with five degrees of freedom per node, three translations and two rotations. It is based on the element presented by Razaqpur et al. [21], named IDKQ and developed from the discrete hypotheses of Kirchhoff. Different from the Razaqpur element, the element implemented in this paper contains the translation degrees of freedom in $x$ and $y$ directions, as the nonlinear analysis and joint action of the concrete slab and the steel sheeting do not allow to know the position of the neutral plane for which the displacements are zero.

The four-node element for analysis of thin flat shells is developed from the thick flat shell element of the previous item by eliminating of the vertical translation degree of freedom. The formulation is developed for the nine-node element and the displacements found are transformed to the four-node element through a transformation matrix.

As for the flat-shell element (item 3.1), the displacements for the thin shell element are given by Eqs. 2 to 4 . Assuming now that $\theta_{x}=w_{y}$ and $\theta_{y}=w_{x}$, it is assumed that $\varepsilon_{x z}=\varepsilon_{y z}=0$, and the other strains are given by equations 9 to 11 . It is observed from these equations that the transverse displacement is no longer an explicit unknown of the problem, this being the only difference in the formulations in that first part.

$\varepsilon_{x}=u_{, x}+z \theta_{y, x}+\frac{1}{2} \theta_{y}^{2}$

$\varepsilon_{y}=v_{, y}+z \theta_{x, y}+\frac{1}{2} \theta_{x}^{2}$

$\varepsilon_{x y}=\frac{1}{2}\left(u_{, y}+z \theta_{y, y}+v_{, x}-z \theta_{x, x}-\theta_{y} \theta_{x}\right)$

Following the same line of reasoning in item 3.1 to obtain the weak formulation of the internal virtual work and equating to the external virtual work arrives at the vector of internal forces for the thin shell element given by the following equation.

$\boldsymbol{f}_{i n t}=\iint_{A}\left\{\begin{array}{c}N_{x} \boldsymbol{\Phi}_{, x}+N_{x y} \boldsymbol{\Phi}, y \\ N_{x y} \boldsymbol{\Phi}_{, x}+N_{y} \boldsymbol{\Phi}_{, y} \\ -M_{x y} \boldsymbol{\Phi}_{, x}-M_{x} \boldsymbol{\Phi}_{, y}+\theta_{x} N_{y} \boldsymbol{\Phi}-\theta_{y} N_{x y} \boldsymbol{\Phi} \\ M_{y} \boldsymbol{\Phi}_{, x}+M_{x y} \boldsymbol{\Phi}_{, y}+\theta_{y} N_{x} \boldsymbol{\Phi}-\theta_{x} N_{x y} \boldsymbol{\Phi}\end{array}\right\} d A$

Different from item 3.1, the vector $\Phi$ representing the form functions evaluated at a given point has 36 terms, as the degrees of freedom relative to the vertical displacement are not being considered in this formulation. However, for the other degrees of freedom the form functions are the same as in item 3.1. Analogous to item 3.1, the tangent stiffness matrix is given by the vector of internal forces in relation to the nodal displacements.

$\mathbf{K}=\iint_{A}\left[\begin{array}{c}\boldsymbol{\Phi}_{, x}\left(\frac{\partial N_{x}}{\partial \mathbf{q}}\right)^{T}+\boldsymbol{\Phi}_{, y}\left(\frac{\partial N_{x y}}{\partial \mathbf{q}}\right)^{T} \\ \boldsymbol{\Phi}_{, x}\left(\frac{\partial N_{x y}}{\partial \mathbf{q}}\right)^{T}+\boldsymbol{\Phi}_{, y}\left(\frac{\partial N_{y}}{\partial \mathbf{q}}\right)^{T} \\ -\boldsymbol{\Phi}_{, x}\left(\frac{\partial M_{x y}}{\partial \mathbf{q}}\right)^{T}-\boldsymbol{\Phi}_{, y}\left(\frac{\partial M_{x}}{\partial \mathbf{q}}\right)^{T}+\boldsymbol{\Psi}_{1} \\ \boldsymbol{\Phi}_{, x}\left(\frac{\partial M_{y}}{\partial \mathbf{q}}\right)^{T}+\boldsymbol{\Phi}_{, y}\left(\frac{\partial M_{x y}}{\partial \mathbf{q}}\right)^{T}+\boldsymbol{\Psi}_{2}\end{array}\right] d A$

The thin flat shell element formulation developed in this item thus far is based on the formulation of the thick flat shell element of item 3.1. The Kirchhoff hypotheses are forced by making the degrees 


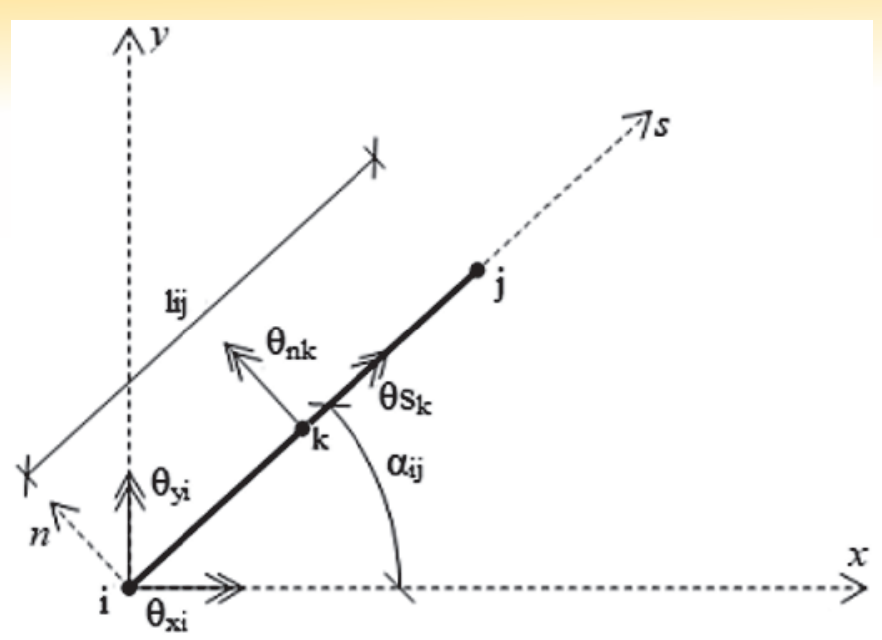

Figure 6

Element-side coordinates (adapted of [21])

of freedom of rotation equal to those derived from the vertical displacement, and thus canceling the shear stresses. However, the obtained formulation cannot be used because its form functions consider independence of the rotations in $x$ and $y$, which in Kirchhoff's theory does not happen. Razaqpur et al. [21] defined a transformation matrix that alters the formulation obtained so far in a consistent formulation for a four-node thin flat shell element. This transformation matrix is shown below and, unlike Razaqpur, in this paper it is considered the membrane effect.

To write the displacements of the four-node element, it is required to do a conversion through a transformation matrix $\left(T_{n \times m}\right)$, so that: $q=T_{n \times m} p, n$ is the number of degrees of freedom of the 9 -node element, $m$ is the number of degrees of freedom of the 4-node element,

$\mathbf{q}^{T}=\left\{\begin{array}{llllllllllll}u_{1} & \cdots & u_{9} & v_{1} & \cdots & v_{9} & \theta_{x 1} & \cdots & \theta_{x 9} & \theta_{y 1} & \cdots & \theta_{y 9}\end{array}\right\}$, and $\mathbf{p}^{T}=\left\{\begin{array}{lllllllllllll}u_{1} & \cdots & u_{4} & v_{1} & \cdots & v_{4} & w_{1} & \theta_{x 1} & \theta_{y 1} & \cdots & w_{4} & \theta_{x 4} & \theta_{y 4}\end{array}\right\}$.

A side of the nine-node quadrilateral element is shown in Figure 6 . Using an interpolation function that associates the vertical displacement along the axis $i-j$ and its derivative with respect to the variable along this axis, it can be relate the vertical displacement and its derivatives in the nodes $i-j$ with the rotations of the element of nine nodes.

For directions $u$ and $v$, the displacements of the vertices of the ninenode element are equal to the displacements of the vertices of the four-node element. For the central nodes on each side of the ninenode element, the displacements $u$ and $v$, are calculated by the mean of the displacements of the nodes of the vertices of the fournode element. That is, $u_{k}=\left(u_{i}^{*}+u_{j}^{*}\right) / 2$. For node 9 , inner node of the quadrilateral element, the displacements $u$ and $v$ are calculated by using of the displacements of the central nodes of the element contour, which were calculated using the mean of the vertex nodes of the element, thus: $u_{9}=\left(u_{1}{ }^{*}+u_{2}{ }^{*}+u_{3}{ }^{*}+u_{4}{ }^{*}\right) / 4$ and $v_{9}=\left(v_{1}{ }^{*}+v_{2}{ }^{*}+v_{3}{ }^{*}+v_{4}{ }^{*}\right) / 4$.

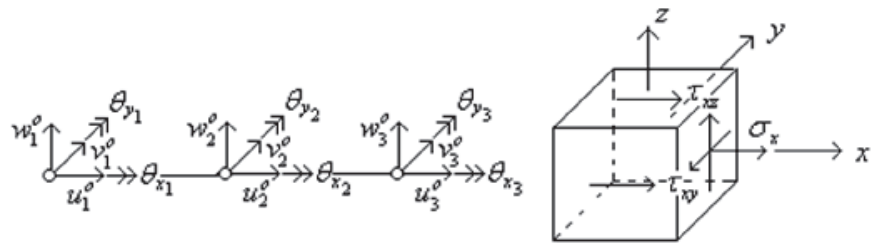

\section{Figure 7}

Beam element's degrees of freedom and stress in an infinitesimal element
The subscript * indicates displacements in the four-node element, that is, terms of the vector $\mathbf{p}$.

Given $\mathbf{T}_{n \times m}$, the tangent stiffness matrix for the four-node element is given by $\mathbf{K}_{m \times m}^{*}=\mathbf{T}_{m \times n}^{T} \mathbf{K}_{n \times n} \mathbf{T}_{n \times m} ; \mathbf{K}_{n \times n}$ is the stiffness matrix of the 9-node element given by Eq. 13. The transformation matrix $\mathbf{T}_{n \times m}$ required to transform the stiffness matrix of the 9-node element to the 4 -node element is formed by 36 rows and 20 columns.

\subsection{Beam element}

In the composite slab numerical simulation, the concrete ribs are simulated by beam elements. The Figure 7 shows the degrees of freedom considered in implementing the beam element and the stress that arise in an infinitesimal element of the beam. It is observed that the degrees of freedom of the beam element are the same as those adopted for the flat shell element.

Considering the kinematic hypotheses of Tymoshenko's beam theory and the approximation that a torsional stress does not cause displacements outside the torsion plane, the following equations of displacement are defined.

$u(x, y, z)=u^{0}(x)+z \theta_{y}(x)$

$v(x, y, z)=v^{0}(x)-z \theta_{x}(x)$

$w(x, y, z)=w^{0}(x)+y \theta_{x}(x)$

By defining the internal forces in the cross-section of the beam element $N_{x}=\int_{A} \sigma_{x} d A, N_{x y}=\int_{A} \tau_{x} d A, N_{x z}=\int_{A} \tau_{x z} d A, M_{x}=\int_{A} \sigma_{x} z d A$ and $T_{x}=\int_{A}\left(\tau_{x z} y-T_{x y} z\right) d A$, and approaching the equations of displacements by functions of forms associated with nodal displacements, are generated Eq. 17 and 18, for the weak formulation of the virtual work and tangent stiffness matrix, respectively. In both equations, $\Phi$ it is a vector that represents the form functions given by quadratic polynomials for the axial, transverse and rotational displacements, $q=\left[u_{i} v_{i} w_{i} \theta_{x i} \theta_{y i}\right]^{\top}$ with $i$ varying from 1 to 3 (number of nodes of the bar element) represents the degrees of freedom of the bar element.

$\mathbf{f}_{i n t}=\int_{L}\left\{\begin{array}{c}N_{x} \boldsymbol{\Phi}_{, x} \\ N_{x y} \boldsymbol{\Phi}_{, x} \\ \frac{5}{6} N_{x z} \boldsymbol{\Phi}_{, x}+N_{x} \boldsymbol{\Phi}_{, x} w_{, x} \\ T_{x} \boldsymbol{\Phi}_{, x} \\ M_{x} \boldsymbol{\Phi}_{, x}+\frac{5}{6} N_{x z} \boldsymbol{\Phi}\end{array}\right\} d x$

$\boldsymbol{K}=\int_{L}\left[\begin{array}{c}\boldsymbol{\Phi}_{, x}\left(\frac{\partial N_{x}}{\partial \boldsymbol{q}}\right)^{T} \\ \boldsymbol{\Phi}_{, x}\left(\frac{\partial N_{x y}}{\partial \boldsymbol{q}}\right)^{T} \\ \boldsymbol{\Phi}_{, x}\left(\frac{\partial N_{x z}}{\partial \boldsymbol{q}}\right)^{T}+\boldsymbol{\Phi}_{, x} w_{, x}\left(\frac{\partial N_{x}}{\partial \boldsymbol{q}}\right)^{T}+N_{x} \boldsymbol{\Phi}_{, x}\left(\frac{\partial w_{, x}}{\partial \boldsymbol{q}}\right)^{T} \\ \boldsymbol{\Phi}_{, x}\left(\frac{\partial T_{x}}{\partial \boldsymbol{q}}\right)^{T} \\ \boldsymbol{\Phi}_{, x}\left(\frac{\partial M_{x}}{\partial \boldsymbol{q}}\right)^{T}+\boldsymbol{\Phi}\left(\frac{\partial N_{x y}}{\partial \boldsymbol{q}}\right)^{T}\end{array}\right] d x$

\subsection{Interface element}

For the simulation of the deformable connection between concrete slab and steel sheeting, the interface element shown in Figure 8 is used. This element connects the beam element that represent the concrete rib to the flat shell elements of concrete and steel. The interface element used to connect concrete flat shell elements 

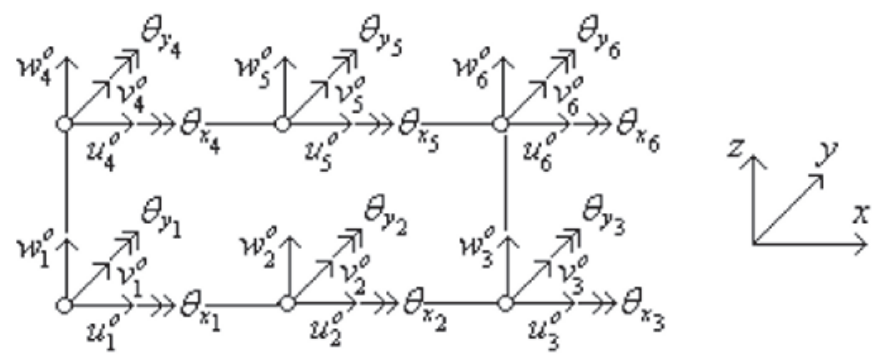

\section{Figure 8}

Interface element's degrees of freedom

to steel flat shell elements is similar thereto. For further details of these elements refer to Silva and Dias [29].

As $u_{\alpha}(x, y, z)=u_{\alpha}^{0}(x)+z \theta_{y \alpha}(x)$ and $v_{\alpha}(x, y, z)=v_{\alpha}^{0}-z \theta_{x \alpha}(x)$, the displacements equations in $x$ and $y$ directions for the above $(\alpha=1)$ and below $(\alpha=2)$ elements of the contact interface, and considering $\mathrm{w}_{\alpha}(\mathrm{x}, \mathrm{y}, \mathrm{z})=\mathrm{w}_{\alpha}{ }^{0}(\mathrm{x})+\mathrm{y}_{\mathrm{xa}}^{\theta}(\mathrm{x})$ as the displacement equation in the $z$ direction, Equations 19-21 for relative longitudinal displacements ( $x$-direction), transverse ( $y$-direction), and vertical (z-direction) of the interface element of Figure 8, is generated.

$s_{l}(x)=u_{2}^{0}(x)-u_{1}^{0}(x)-\left(y_{2}-d\right) \theta_{y 2}(x)-\left(d-y_{1}\right) \theta_{y 1}(x)$

$s_{t}(x)=v_{2}^{0}(x)-v_{1}^{0}(x)+\left(y_{2}-d\right) \theta_{x 2}(x)+\left(d-y_{1}\right) \theta_{x 1}(x)$

$s_{v}(x)=w_{2}^{0}(x)-w_{1}^{0}(x)+y\left(\theta_{x 2}(x)-\theta_{x 1}(x)\right)$

The relative displacement in the $\mathrm{x}$-direction and the variables appearing in Equations 19 to 21, $d, y_{1}$ and $y_{2}$, are shown in Figure 9. The superscript ${ }^{0}$ indicates displacement on a plane or an adopted reference axis. This index will be omitted from the equations below to facilitate the notation.

Defining $S_{b}, V_{b}$ and $N_{b}$ forces per unit length in the direction of $\mathrm{u}, \mathrm{v}$ and $\mathrm{w}$, respectively, $\mathrm{b}$ the width of the contact represented by the interface element, then $\mathrm{Sb} / \mathrm{b}$ provides the shear stress in the longitudinal direction of the contact. Since $N_{b}{ }^{1}=\int_{b} N_{b} d y$ and $N_{b}{ }^{2}=\int_{b} N_{b} d y, \Phi$ is a vector where its terms are functions of quadratic polynomials, $q$ is the vector of nodal displacements, Eq. 22 and 23 for the internal forces vector and the tangent stiffness matrix of the interface element are generated.

$\mathbf{f}_{\text {int }}=\int_{L}\left\{\begin{array}{c}-S_{b} \boldsymbol{\Phi} \\ -V_{b} \boldsymbol{\Phi} \\ -N_{b}^{1} \boldsymbol{\Phi} \\ {\left[\left(d-y_{1}\right) V_{b}-N_{b}^{2}\right] \boldsymbol{\Phi}} \\ \left(y_{1}-d\right) S_{b} \boldsymbol{\Phi} \\ S_{b} \boldsymbol{\Phi} \\ V_{b} \boldsymbol{\Phi} \\ N_{b}^{1} \boldsymbol{\Phi} \\ {\left[\left(y_{2}-d\right) V_{b}+N_{b}^{2]}\right] \boldsymbol{\Phi}} \\ \left(d-y_{2}\right) S_{b} \boldsymbol{\Phi}\end{array}\right\} d x$

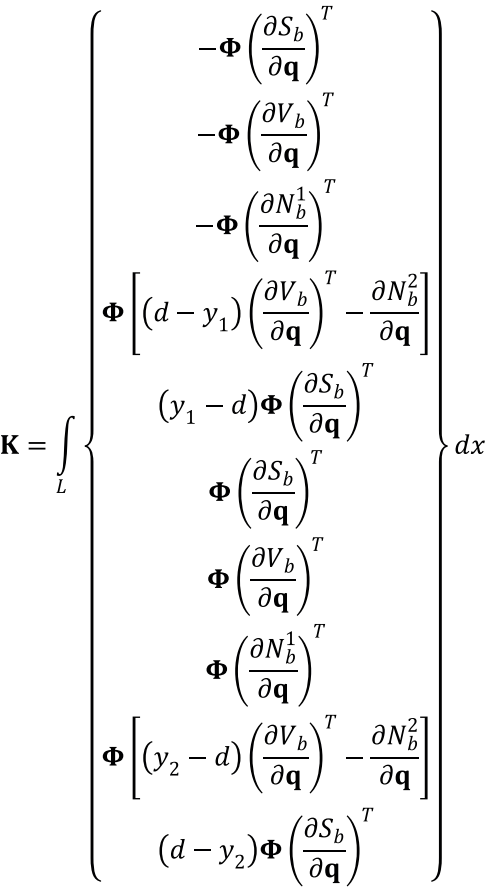

\section{Numerical analysis}

For the validation of the analysis model and the finite elements suggested in this paper, numerical and experimental

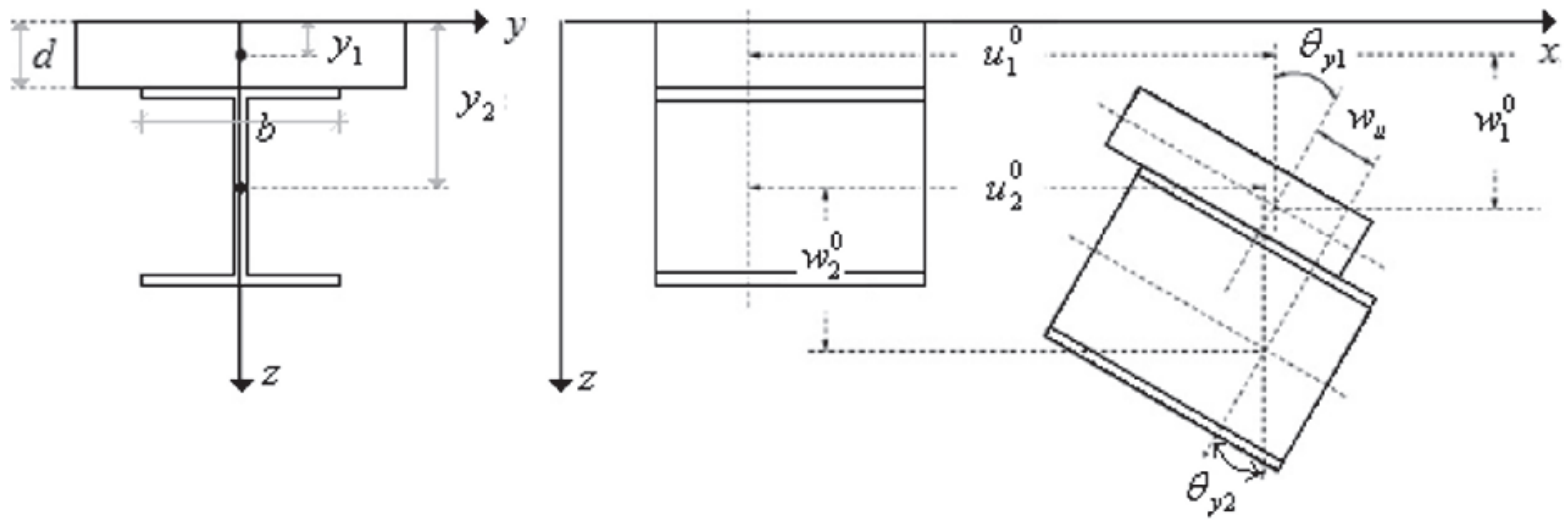

Figure 9

Longitudinal slip 


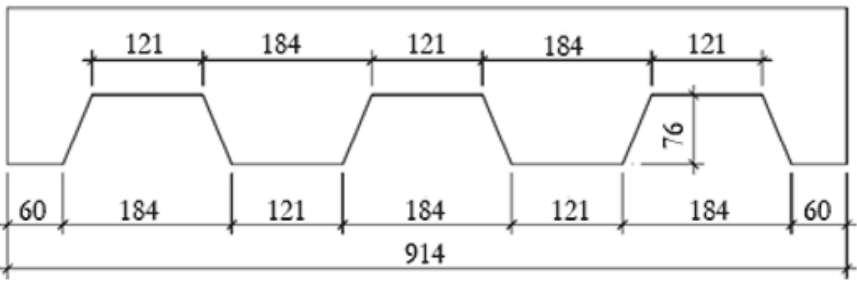

\section{Figure 10}

Steel deck dimensions [9] (dimensions in $\mathrm{mm}$ )

published results that are used. Three examples are presented below.

\subsection{Example 1: bending test}

A typical bending test of composite slabs, as shown in Figure 1, is modeled. The slab was studied experimentally by Chen [25] and numerically analyzed by Chen and Shi [9]. Two analysis are performed. In the first, two thin flat elements are used, one for modeling the steel sheeting and the other for the concrete slab above the rib, as shown in Figure 4. In the second analysis, the thick flat shell element is used to model the concrete slab above the rib and the thin flat shell element to model the steel sheeting. In both analysis, the rib is simulated by the beam element and the connection between the different elements and the simulation of the deformable connection is made by the interface elements shell/shell and beam/shell. The slab is $0.914 \mathrm{~m}$ wide, $2.6 \mathrm{~m}$ long and two loads are applied following the indicated for the bending test (shown in Figure 1), with a shear span of $0.65 \mathrm{~m}$. The total concrete thickness is $165 \mathrm{~mm}$. A detail of the steel sheeting having a thickness of $0.9 \mathrm{~mm}$ is shown in Figure 10.

Figure 11 shows the discretization of the composite slab, to the interface elements are in gray. The stress-strain curves described in the formulations of the elements were used to characterize the materials, and the elastic modulus $\mathrm{E}_{\mathrm{c}}=27133 \mathrm{MPa}$, compressive strength $\mathrm{fc}=20.1 \mathrm{MPa}$ and Poisson's coefficient $\mathrm{v}=0.2$ was used for the concrete. The elastic modulus $\mathrm{E}_{\mathrm{s}}=210000 \mathrm{MPa}$, yield stress fy $=275 \mathrm{MPa}$, and the Poisson coefficient $v=0.3$ are used for the steel sheeting. As shown in Figure 11, due to the symmetry with respect to the $y z$ plane and given that the slab is formed by joining several cross sections as indicated in the figure, only one rib and one half of the span of the composite slab are discretized. In Figure 11, the conditions of support and the position of applica-

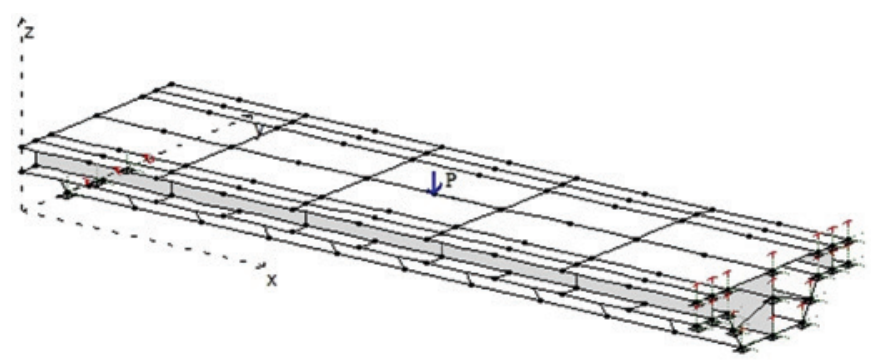

Figure 11

Composite slab model

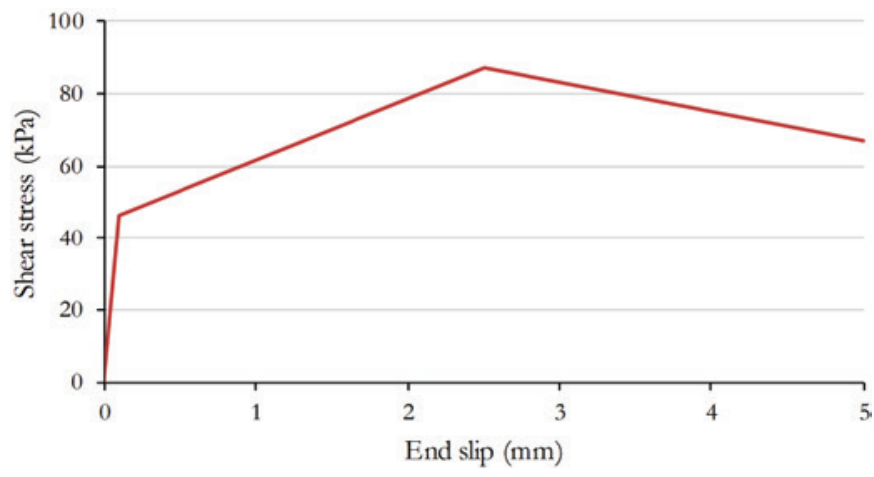

Figure 12

Shear stress $\mathrm{x}$ end slip curve

tion of the load are also shown. The three nodes marked on the left-hand end present translational displacements along the $x$-axis and rotation on $y$ released. Those of the right end have only the free $z$-translation.

The connection between the steel and the concrete was modeled by the interface elements that have three stiffnesses, longitudinal, transverse and vertical. As the failure in composite slabs occurs due to longitudinal shear, the possibilities of vertical separation and transversal sliding are disregarded. Thus, a linear curve representing total connection, that is, high stiffness $\mathrm{E}=106 \mathrm{MPa}$ is used to represent the contact in the transverse and vertical direction. For longitudinal stiffness the results provided by Chen [9] about the load versus end slip curve of the composite slab were used to define the shear stress versus longitudinal slip at the steel-concrete contact of the composite slab. For the curve shown in Figure 12, it is assumed a function defined by sentences, where each sentence is given by the equation of a line. The limits of each sentence interval as well as the linear and angular coefficients of the line equation are defined so that the numerical and experimental load-slip response to the composite slab are quite close.

The results of Chen and Shi [9] were generated with the software ANSYS, in which the steel sheeting was discretized with shell elements, the concrete slab with solid elements, and the deformable connection was modeled by a pair of contact elements, considering adhesion and friction. Figures 13 and 14 shown the results

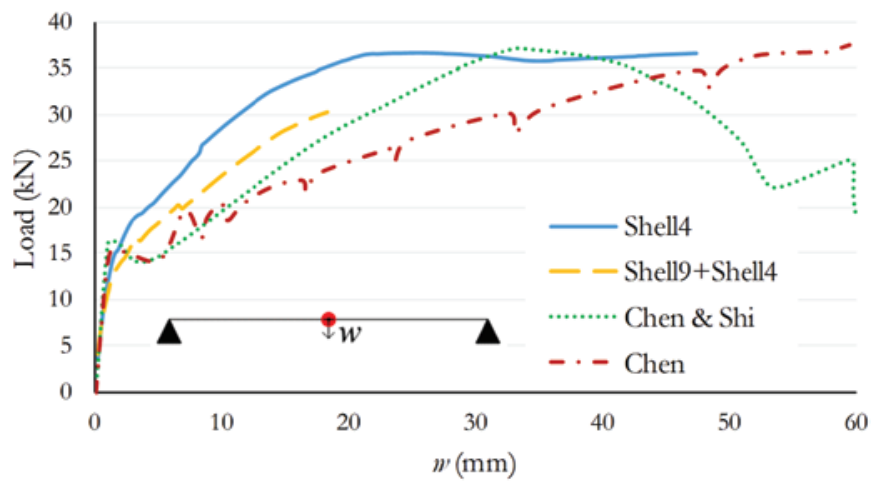

Figure 13

Load x mid-span deflection curve 


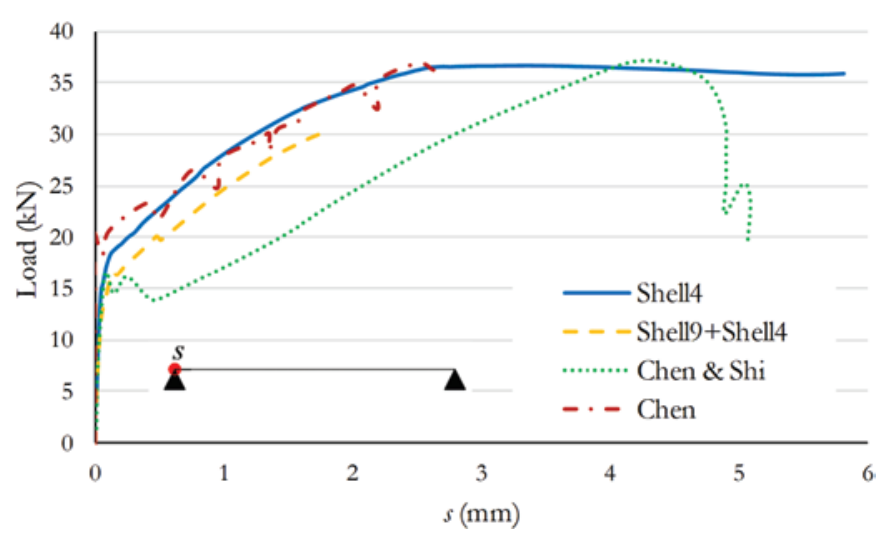

Figure 14

Load $x$ end slip curve

obtained in this paper, as well as those gotten by Chen and Shi [9] and Chen [25]. The label (shell4) refers to the analysis using only the thin flat shell element and the label (shell9 + shell4) to the analysis using the two elements.

Figure 13 shows the behavior of the deflection in the mid-span of the composite slab in relation to the applied load. In the two analysis, the behavior obtained for the linear phase, in which there is total interaction between the steel and the concrete, was similar to the experimental behavior. With the beginning of the nonlinear behavior, there is difference between the experimental behavior and the behavior found with the numerical models. This difference is due to the complexity of the numerical simulation of the concrete after cracking and the large number of factors that influence the behavior of the contact in composite slabs, such as localized effects in the embossments. However, in terms of ultimate load, the values gotten in only the thin flat shell elements (Shell4), and the numerical response of Chen, are similar to the experimental result. The analysis (Shell9 + Shell4) has a slightly lower value, which can be explained by the difference in the formulations of the elements, considering that Shell9 element can have the shear locking effect. Figure 14 shows the slip behavior at the end of the slab with respect to the applied load. It is worthwhile that all numerical analysis of have behavior close to the real at the beginning of the linear behavior phase. In terms of ultimate load, both the Chen and Shi analysis [25] and the analysis using only the thin flat shell element (Shell4) generated results close to the experimental results. However, it is observed that in the analysis with the thin shell element (Shell4) the nonlinear phase behavior is very close to the actual

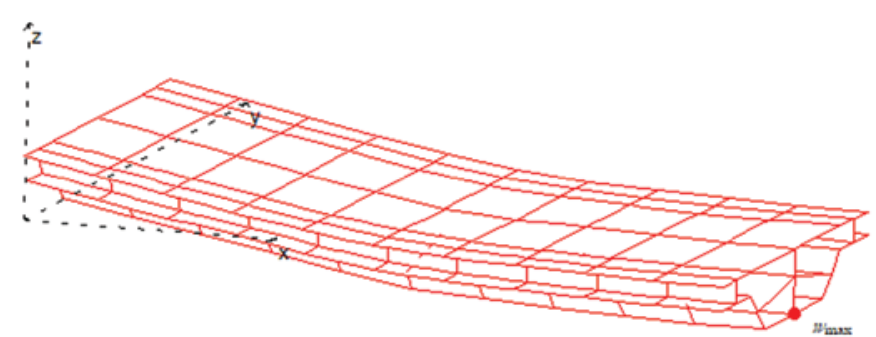

Figure 15

Deflected shape of the composite slab

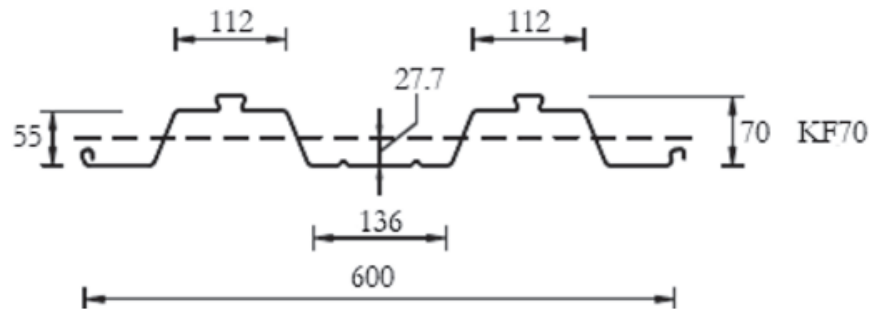

Figure 16

Steel decking profile [10] (dimensions in $\mathrm{mm}$ )

behavior, which does not occur in the numerical analysis of Chen and Shi. For the analysis (Shell9+Shell4) the same considerations are given for the load-displacement curve of the Figure 13.

Figure 15 shows the deformed slab and the point of maximum deflection. This deflection was obtained for the nonlinear phase of the load-displacement curve and there is a greater curvature of the composite slab at the application point of the load. This justifies the fact that some authors add elements (cracking inducers) in this point that may represent concrete behavior after cracking [7].

\subsection{Example 2: continuous slab}

A composite slab with two symmetrical continuous spans in terms of loading and support conditions is analyzed. The steel sheeting is shown in Figure 16. This same composite slab was numerically and experimentally evaluated by Gholamhoseini et al. [10].

Transverse and longitudinal reinforcement were used in the negative moment region. The loading is as indicated for the bending test. Figures 17 and 18 show a detail of the negative reinforcements and a scheme of a continuous slab span, respectively.

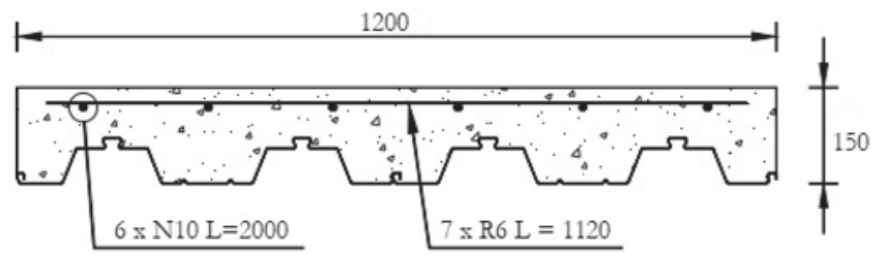

Figure 17

Reinforcement details at interior support [10] (dimensions in $\mathrm{mm}$ )

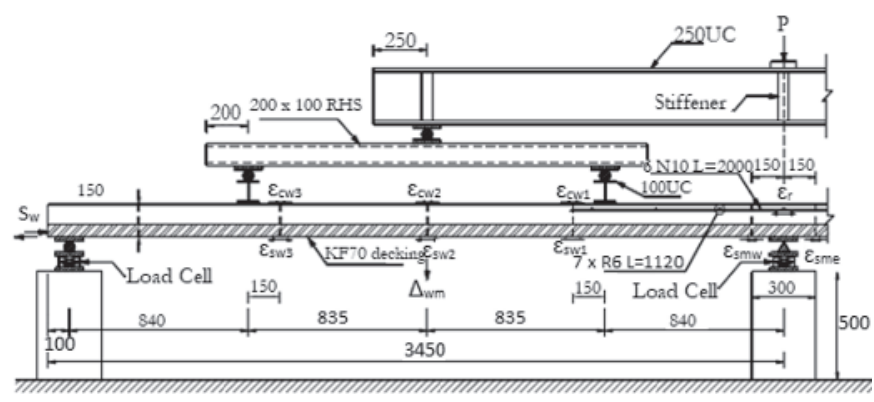

Figure 18

Continuous slab scheme [10] (dimensions in $\mathrm{mm}$ ) 


\section{Table 1}

KF-70 slab characteristics

\begin{tabular}{cccccc}
\hline Slab & $\begin{array}{c}\text { Width } \\
(\mathrm{m})\end{array}$ & $\begin{array}{c}\text { Total length } \\
(\mathrm{m})\end{array}$ & $\begin{array}{c}\text { Total thickness } \\
(\mathrm{mm})\end{array}$ & $\begin{array}{c}\text { Span } \\
(\mathrm{mm})\end{array}$ & $\begin{array}{c}\text { Shear span } \\
(\mathrm{mm})\end{array}$ \\
\hline $\mathrm{KF}-70$ & 1.2 & 6.9 & 150 & 3350 & $\mathrm{~L} / 4=837.5$ \\
\hline
\end{tabular}

Table 2

Materials properties

\begin{tabular}{cccccc}
\hline Slab & $\begin{array}{c}\mathbf{f}^{\prime}{ }_{c} \\
(\mathbf{M P a})\end{array}$ & $\begin{array}{c}\mathbf{E}_{\mathrm{c}} \\
(\mathrm{MPa})\end{array}$ & $\begin{array}{c}\mathbf{f}_{\mathrm{y}} \\
(\mathbf{M P a})\end{array}$ & $\begin{array}{c}\mathbf{E}_{\mathrm{s}} \\
(\mathrm{GPa})\end{array}$ & $\begin{array}{c}\text { Sheeting thickness } \\
(\mathbf{m m})\end{array}$ \\
\hline KF-70 & 47.9 & 33050 & 532 & 203 & 0.75 \\
\hline
\end{tabular}

Table 1 shows the dimensions and shear span of the slab evaluated. Two analysis (shell4) and (shell9+shell4) are performed, both analysis have already been described in the previous example.

As previously, the vertical separation and the transversal sliding are disregarded, as the longitudinal connection is represented by a shear versus slip curve at the steel-concrete contact of the composite slab as shown in Figure 19. This curve was determined from experimental response of the load-slip end curve of the continuous slab provided by Gholamhoseini et al. [10].

The concrete and steel decking materials are characterized by their stress-strain curves, and the values given in Table 2 are used. The reinforcements yield stress is $f y=495 \mathrm{MPa}$ and the elasticity modulus $E_{s}=205 \mathrm{GPa}$.

The numerical results of Gholamhoseini et al. [10] were obtained with the ATENA 3D software. The steel sheeting and the concrete slab were modeled with solid tetrahedral elements; the reinforcements were modeled as discrete bars within the concrete slab, and the connection between the steel and the concrete was simulated through an interface material that is based on the Mohr-Coulomb failure criterion. The numerical results obtained in this paper and the Gholamhoseini numerical and experimental results are indicated in Figures 20 and 21.

The load-displacement and load-end slip curves of the composite slab are shown in Figures 20 and 21 respectively. The numerical analysis provided a good approximation with the experimental analysis. The numerical analysis of Gholamhoseini is not presented in Figure 21, because it was not provided by the author.

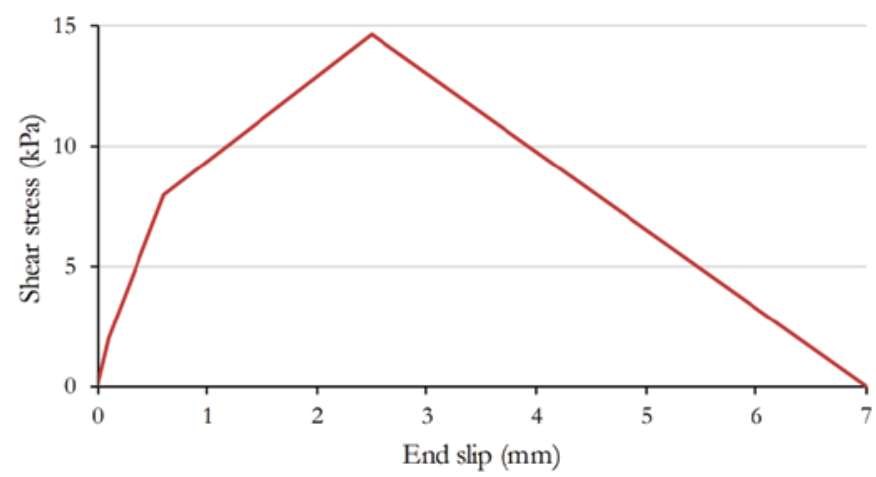

Figure 19

Shear stress $x$ end slip curve

\subsection{Example 3: slab with dovetail rib profiled sheeting}

Like trapezoidal steel decking, reentrant steel decking is widely used in composite slabs. In this case, no embossments are used, because steel decking geometry generates a confinement effect of the concrete, which contributes to the shear strength at the steelconcrete interface. In this example, the two composite slabs with the reentrant steel decking shown in Figure 22 are modeled. The slabs in question were experimentally studied by Marciukaitis et al. [32] and evaluated numerically by Chen and Shi [9].

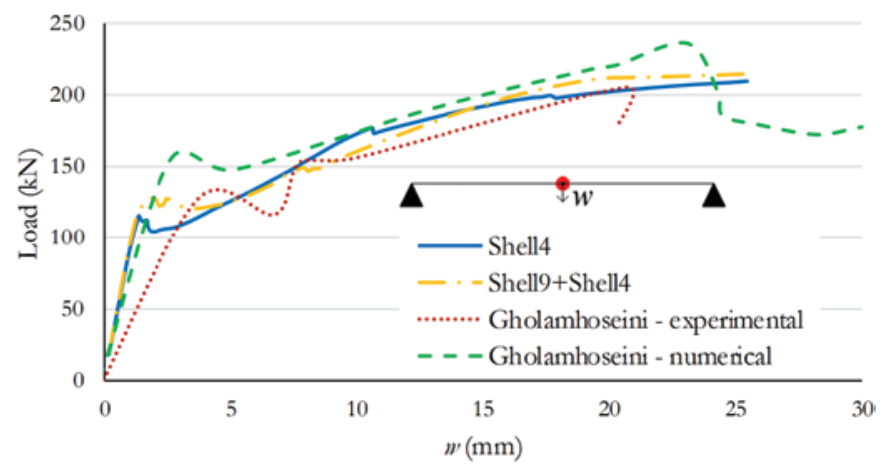

Figure 20

Load x mid-span deflection curve

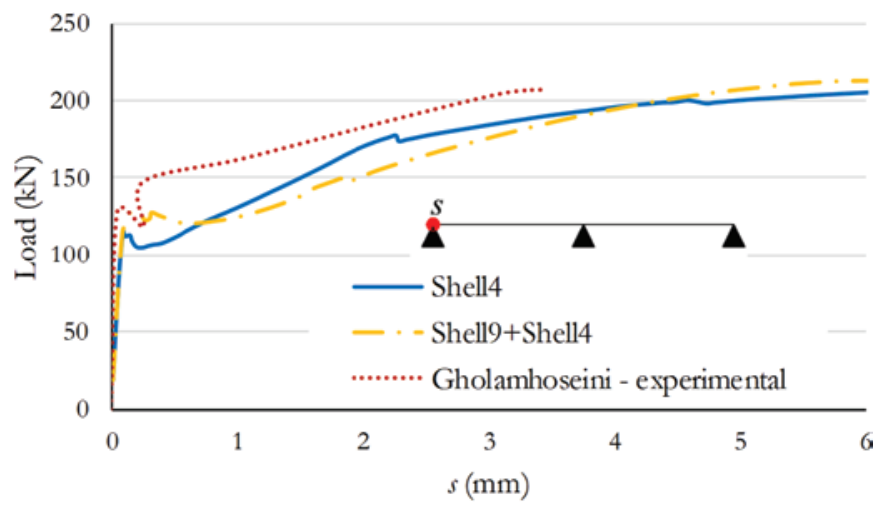

Figure 21

Load $x$ end slip continuous slab curve 


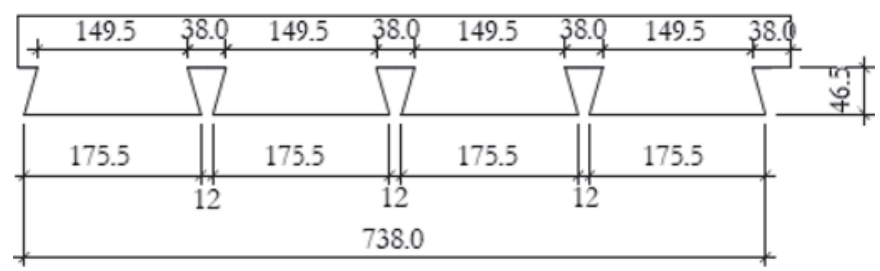

Figure 22

Steel deck dimensions [9] (dimensions in $\mathrm{mm}$ )

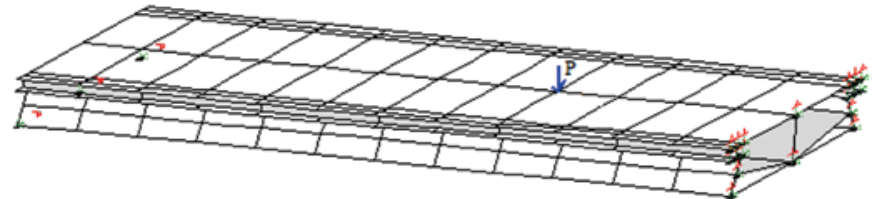

Figure 23

PI-2 slab model

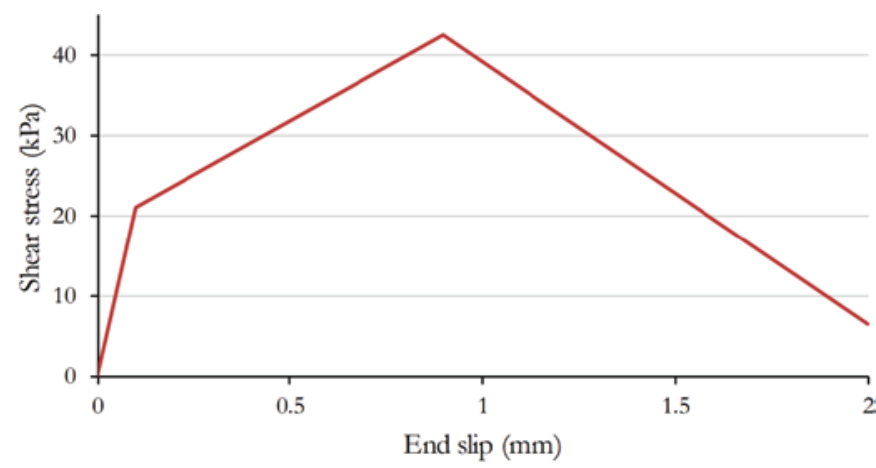

Figure 24

Shear stress $x$ end slip curve

Table 3 shows the dimensions and shear span of the slabs evaluated. The slabs have two loads applied symmetrically according to the bending test. Two analysis (shell4) and (shell9+shell4) are performed, both analysis have already been made in the previous examples.

Figure 23 presents the slab P1-2 discretization. As can be seen in this discretization and in the other examples, the beam element representing the concrete in the rib is not located in the geometric center of its cross section. That is because the interface element that connects the beam element and the flat shell element must have $90^{\circ}$ as the slip plane, which in these examples is parallel to the flat shell element. This figure also shows the conditions of support and the position of application of the load. The three leftmost nodes, that are marked, have the translation displacements along the $x$-axis and $y$-rotation, and the right-hand nodes have only the free $z$-translation.

As in the previous examples, the possibilities of vertical separation and transverse slip were disregarded. For the connection in the longitudinal direction the shear stress versus longitudinal slip curve given in Figure 24 is used. This curve was generated in a similar way as suggested by Marciukaitis et al. [32]. The materials properties are shown in Table 4.

The numerical results of Chen and Shi [9] were obtained with the commercial software ANSYS. The steel sheeting was discretized with flat shell elements, the concrete slab with solid elements and the connection was modeled by a pair of contact elements, allowing only longitudinal sliding. Figures 25 and 26 shows the numerical results obtained in this paper, the numerical results of Chen and Shi [9], and the results of the experimental model presented by Marciukaitis et al. [32].

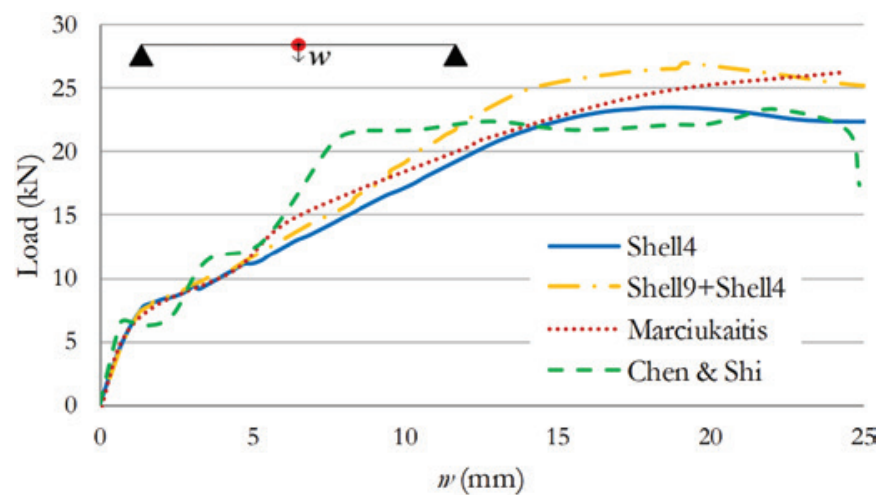

Figure 25

P1-2 slab - Load x mid-span deflection curve

\section{Table 3}

Slabs dimensions

\begin{tabular}{cccccc}
\hline Slab & $\begin{array}{c}\text { Span } \\
(\mathrm{m})\end{array}$ & $\begin{array}{c}\text { Width } \\
(\mathrm{m})\end{array}$ & $\begin{array}{c}\text { Sheeting thickness } \\
(\mathrm{mm})\end{array}$ & $\begin{array}{c}\text { Concrete's total thickness } \\
(\mathrm{mm})\end{array}$ & $\begin{array}{c}\text { Shear span } \\
(\mathrm{m})\end{array}$ \\
\hline P1-2 & 1.8 & 0.77 & 0.9 & 75 & 0.6 \\
P2-2 & 1.8 & 0.77 & 0.9 & 98 & 0.6 \\
\hline
\end{tabular}

\section{Table 4}

Materials properties

\begin{tabular}{ccccccc}
\hline Slab & $\begin{array}{c}\mathbf{f}_{\mathrm{y}} \\
(\mathbf{M P a})\end{array}$ & $\begin{array}{c}\mathbf{E}_{s} \\
(\mathbf{G P a})\end{array}$ & $v_{s}$ & $\begin{array}{c}\mathbf{f}_{c} \\
(\mathbf{M P a})\end{array}$ & $\begin{array}{c}\mathbf{E}_{\mathrm{c}} \\
(\mathbf{G P a})\end{array}$ & $v_{c}$ \\
\hline P1-2 & 317 & 205 & 0.3 & 21.6 & 40.5 & 0.2 \\
P2-2 & 317 & 205 & 0.3 & 28.6 & 41.5 & 0.2 \\
\hline
\end{tabular}




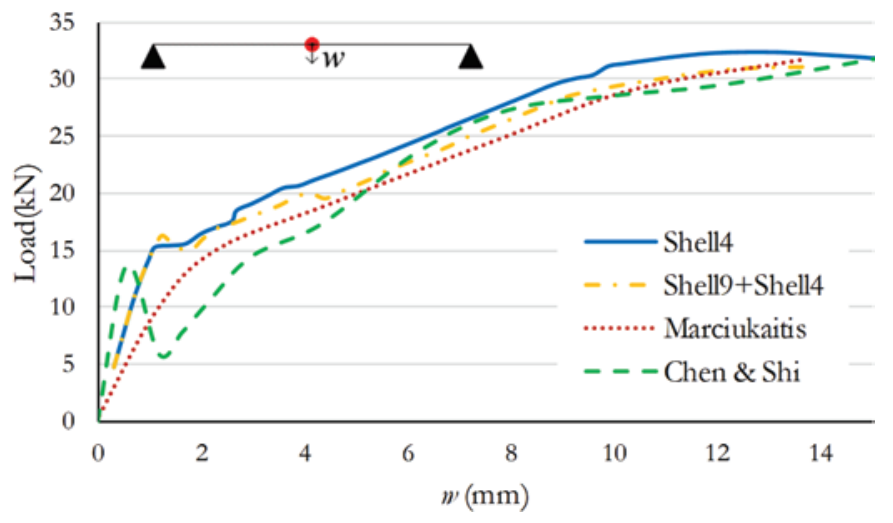

Figure 26

P2-2 slab - Load x mid-span deflection curve

From Figures 25 and 26, in the two analysis the behavior obtained for the numerical models implemented in this paper was close to the behavior of the experimental model. In general, the numerical models developed in this paper have gotten results that better represent the load-deflection behavior for the slab P1-2 and P2-2 than the reference numerical model.

\section{Conclusions}

In this paper it is proposed a finite element analysis model for nonlinear numerical analysis of composite slabs submitted to their ultimate capacity. In this model, the concrete slab above the ribs is simulated by shell elements considering the orthotropic behavior of the concrete after cracking and steel after the yielding. The deformable connection between the steel sheeting and the concrete is modeled with interface elements and the ribs of the composite slab are modeled with beam elements.

The efficiency of the used model as well as the finite elements included for numerical simulation of composite slabs was according proven with results obtained in numerical and experimental examples found in the published papers. The suggested numerical model allows obtaining the maximum loads supported by the composite slabs, with the advantage of having a lower computational cost compared to the three-dimensional discretization of the composite slab concrete part. As observed in the examples, the thick shell element can generate numerical errors in some analysis and, therefore, the simulation of the concrete slab above the rib is suggested by thin shell elements.

\section{Acknowledgments}

To Universidade Federal de Ouro Preto / PROPEC, FAPEMIG, CNPq, and CAPES for the financial support.

\section{References}

[1] VELJKOVIC M. Behaviour and resistance of composite slabs - Experiments and finite element analysis, Suécia, 1996, Tese (Doutorado) - Department of Steel Structures, Lulea University of Technology, 181p.
[2] CAMPOS P.C. Efeito da continuidade no comportamento e na resistência de lajes mistas com fôrma de aço incorporada, Belo Horizonte, 2001, Dissertação (Mestrado). Escola de Engenharia, Universidade Federal de Minas Gerais, 136p.

[3] ASSOCIAÇÃO BRASILEIRA DE NORMAS TÉCNICAS. Projeto de estruturas de aço e de estruturas mistas de aço e concreto de edifícios. - NBR 8800, Rio de Janeiro, 2008.

[4] COMITE EUROPÉEN DE NORMALISATION. Design of composite steel and concrete structures. Part 1: General rules and rules for buildings. - EUROCODE 4, 2004.

[5] MARIMUTHU V., SEETHARAMAN S., JAYACHANDRAN S.A., CHELLAPPAN A., BANDYOPADHYAY T.K., DUTTA D. Experimental studies on composite deck slabs to determine the shear bond characteristic $(m-k)$ values of the embosse profiled sheet. Journal of Constructional Steel Research, v. 63, 2006; p.791-803.

[6] ABDULLAH R., EASTERLING W.S. Determination of composite slab strength using a new elemental test method. Journal of Structural Engineering, v. 133, n. 9, 2007; p. 1268-1277.

[7] RÍOS J.D., CIFUENTES H., CONCHAA.M., REGUERA F.M. Numerical modelling of the shear-bond behaviour of composite slabs in four and six-point bending tests. Engineering Structures, v. 133, 2017; p. 91-104.

[8] ABDULLAH R., EASTERLING W.S. New evaluation and modeling procedure for horizontal shear bond in composite slabs. Journal of Constructional Steel Research, v. 65, 2009; p. 891-899.

[9] CHEN S., SHIX. Shear bond mechanism of composite slabs - A universal FE approach. Journal of Constructional Steel Research, v. 67, 2011; p. 1475-1484.

[10] GHOLAMHOSEINI A., GILBERT I., BRADFORD M. Longitudinal shear stress and bond-slip relationships in composite concrete slabs. Engineering Structures, v. 69, 2014; p. 37-48.

[11] MAJDI Y., HSU C.T., ZAREI M. Finite element analysis of new composite floors havind cold-formed steel and concrete slab. Engineering Structures, v. 77, 2014; p. 65-83.

[12] BRADFORD M.A. Generic modelling of composite steelconcrete slabs subjected to shrinkage, creep and thermal strains including partial interaction. Engineering Structures, v. 32, 2010; p. 1459-1465.

[13] FERRER M., MARIMON F., CASAFONT M. An experimental investigation of a new perfect bond technology for composite slabs. Construction and Building Materials, v 166, 2018; p. 618-633.

[14] YU X., HUANG Z., BURGESS I., PLANK R. Nonlinear analysis of orthotropic composite slabs in fire. Engineering Structures, v. 30, 2007, p. 67-80.

[15] TENG X., ZHANG Y. X., LIN X. Two new composite plate elements with bond-slip effect for nonlinear finite element analyses of FRP-strenghtened concrete slabs. Computers and Structures, v. 148, 2014; p. 35-44.

[16] TENG X., ZHANG Y.X. Nonlinear finite element analyses of FRP-strengthened reinforced concrete slabs using a new layered composite plate element. Composite Structures, v. 114, 2014; p. 20-29.

[17] HUANG Z., BURGESS I.W., PLANK R.J. Modelling membrane action of concrete slabs in composite buildings in fire. 
Part I: Theoretical development. Journal of Structural Engineering, n. 8, v. 129, 2003; p. 1093-1102.

[18] BATOZ J.L., BATHE J., HO L.H. A study of three-node triangular plate bending elements. International Journal for $\mathrm{Nu}$ merical Methods in Engineering, v. 15, 1980; p. 1771-1812.

[19] BATOZ J.L., TAHAR M.B. Evaluation of a new quadrilateral thin plate bending element. International Journal for Numerical Methods in Engineering, v. 18, 1982; p. 1655-1677.

[20] SARAWIT A.T., KIM Y., BAKKER. M.C.M., PEKOZ T. The finite element method for thin-walled members-applications. Thin-Walled Structures, v. 41, 3003; p. 191-206.

[21] RAZAQPUR A.G., NOFAL M., VASILESCU A. An improved quadrilateral finite element for analysis of thin plates. Finite Elements in Analysis and Design, v. 40, 2002, p. 1-23.

[22] DANIELS B.J., CRISINEL M. Composite slab behavior and strength analysis. Part 1: Calculation procedure. Journal of Structural Engineering, v. 119, 1993; p. 16-35.

[23] CALIXTO J.M., BRENDOLAN G., PIMENTA R. Estudo comparativo dos critérios de dimensionamento ao cisalhamento longitudinal em lajes mistas de aço e concreto. Revista IBRACON de Estruturas e Materiais, v. 2, n. 2, 2009; p. 124-141.

[24] FERRER M., MARIMON F., CRISINEL M. Designing coldformed steel sheets for composite slabs: An experimentally validated FEM approach to slip failure mechanics. ThinWalled Structures, v. 44, 2007; p. 1261-1271.

[25] CHEN S. Load carrying capacity of composite slabs with various end constraints. Journal of Constructional Steel Research, v. 59, 2003; p. 385-403.

[26] RANA M.M., UY B., MIRZA O. Experimental and numerical study of end anchorage in composite slabs. Journal of Constructional Steel Research, v. 115, 2015; p. 372-386.

[27] DEGTYAREV V.V. Strength of composite slabs with end anchorages. Part 1: Analytical model. Journal of Constructional Steel Research, v. 94, 2013; p. 150-162.

[28] SILVA A.R. Análise numérica de elementos estruturais com interação parcial, Ouro Preto, 2010, Tese (Doutorado) - Escola de Minas, Universidade Federal de Ouro Preto.

[29] SILVA A.R., DIAS L.E.S. An interface element for numerical analysis of flat plate/shell elements with deformable connection, Latin American Journal of Solid Structures, v.15, n.2, 2018; p.1-16.

[30] INTERNATIONAL FEDERATION FOR STRUCTURAL CONCRETE. Fip Bulletin 55: Model Code 2010, First complete draft. CEB/FIP MODEL CODE. Volume 1. 2010.

[31] ROTS J.G., KUSTERS G.M.A, BLAAUWENDRAAD J. The need for fracture mechanics options in finite element models for concrete structures. In: Int. Conf. On Computer Aided Analysis and Design of Concrete Structures, 1984, F. Damjanic et al., eds., Pineridge Press, Part 1, 19-32.

[32] MARCIUKAITIS G., JONAITIS B., VALIVONIS J. Analysis of deflections of composite slabs with profiled sheeting up to the ultimate moment. Journal of Constructional Steel Research, v. 62, 2006; p.820-830. 